\title{
Marine bacteria: A better cleaner-upper?
}

The application of marine biotechnology to environmental problems represents an area of potentially great importance - both environmental and economic - to California and the nation. Research in this field could lead to a range of new processes and products, from identifying harmful bacteria in the ocean to monitoring toxic substances such as pesticides in the environment.

One direction that shows particular promise is the bioremediation of polluted marine environments. (Bioremediation refers to the use of organisms to remove or detoxify pollutants.) Bioremediation is a particularly valuable approach for sensitive environments like wetlands, where conventional techniques are too disruptive. Perhaps the best-known example of marine bioremediation was provided during the cleanup of the Exxon Valdez oil spill, when fertilizer was used to enhance the breakdown of oil by naturally occurring bacteria.

The need for new technologies to address marine pollution is enormous. In California alone, 65,000 tons of toxic wastes are released each year into the air, water and soil, of which a significant amount ends up in the ocean, often in runoff from urban and agricultural areas after heavy rains.

As a result, the water and sediments in California's bays and harbors, like those elsewhere in the country, contain dangerous contaminants. These include excess nutrients, sewage and heavy metals, as well as synthetic organic compounds such as pesticides, polychlorinated biphenyls (PCBs) and polycyclic aromatic hydrocarbons (PAHs) that are resistant to degradation and can therefore persist in the environment.

In recent years, California Sea Grant has encouraged research on environmental applications of marine biotechnology. Two projects have specifically explored the potential of bioremediation using marine bacteria.

In one project, Sea Grant trainee Thomas J. Boyd, working with research microbiologist A.F. Carlucci of UC San Diego's Scripps Institution of Oceanography, looked at the degradation of phenols in the ocean. Phenols are organic compounds that are naturally produced by marine organisms and also released into seawater as a result of power generation, petroleum refining and the production of leather, rubber, textiles and plastics. The project investigated the concentrations and types of specific phenolic compounds in California's nearshore ocean and sought to determine whether marine bacteria have the natural ability to degrade them and, if so, at what rates. Boyd tested bacterial populations from a number of sites off California and found that some bacte-
Spores of the marine Bacillus sp. strain SG-1 are capable of binding and precipitating a variety of heavy metals on the spore surface. As a result, metals are removed from solution and detoxified. In this slide the metal precipitates are readily visualized surrounding the spores. The spores are about $0.3 \times 0.6 \mu \mathrm{m}$ in size.
Wetlands at Green Sands Beach, Mare island Naval Shipyard, Vallejo, CA. The site contains waste associated with sandblasting paint off ships. The material is a mixture of sandblasting abrasives like zinc oxide and paint chips that contain toxic antifouling agents like copper and tributyl tin. Weathering of this material has turned the sands green.

ria are naturally able to biodegrade simple phenolic compounds relatively quickly - most phenols had a half-life in the ocean of only 10 to 20 days.

In a second project, which is presently underway, microbiologist Bradley Tebo, also of Scripps, is focusing on metals in marine sediments. Metals are contaminants that can neither be degraded nor destroyed, and so must be removed before they can move into the food web. He has been looking for bacteria that are capable of concentrating toxic heavy metals in sediments for efficient cleanup and recycling. 
Tebo is focusing on a bacterium whose spores can bind a variety of metals. He hopes to exploit the magnetic properties of the bound metals to remove them from sediments, a process that could not only recover valuable metals for recycling but could also reduce the cost of sediment disposal by $90 \%$ or more. Tebo is presently working with a small California biotechnology firm to make this technology commercially feasible.

Some microorganisms seem capable of evolving abilities to deal with almost any toxic substance, and it is probable that marine microbes can be genetically engineered to be even more effective cleaner-uppers, a possibility that Tebo, among others, is exploring.

The application of biotechnology in the marine environment, in contrast to terrestrial systems, is only now being recognized as an important field for research, development and commercialization. But the development of new, commercially viable technologies for the assessment, monitoring, cleanup and prevention of pollution in coastal and estuarine waters is essential to sustained development of our coastal regions and watershed and requires a long-term commitment to science, education and outreach activities.

-Rosemary Amidei

The author is California Sea Grant's Assistant Director for External Relations.

\section{Further Reading}

Boyd TJ, Carlucci AF. 1993. Degradation rates of substituted phenols by natural populations of marine bacteria. Aquat Toxicol 25:71-82.

Ellwood DC, Hill MJ, Watson JHP. 1992. Pollution control using microorganisms and magnetic separation. In: Fry JC et al. (eds.). Microbial Control of Pollution. New York: Cambridge Univ $\operatorname{Pr}$ 48:59-88.

Pennisi E. 1996. Sorcerers of the sea: Making microbes do our dirty work. BioScience 46(4):236-9.

Tebo BM. 1995a. Metal precipitation by marine bacteria: Potential for biotechnological applications. In: Setlow, JK, (ed). Genetic Engineering - Principles and Methods. New York: Plenum 17:231-63.

Tebo BM. 1995b. Environmental Applications of Marine Biotechnology: Summary of a Workshop. La Jolla (CA): California Sea Grant College System. 32 p.

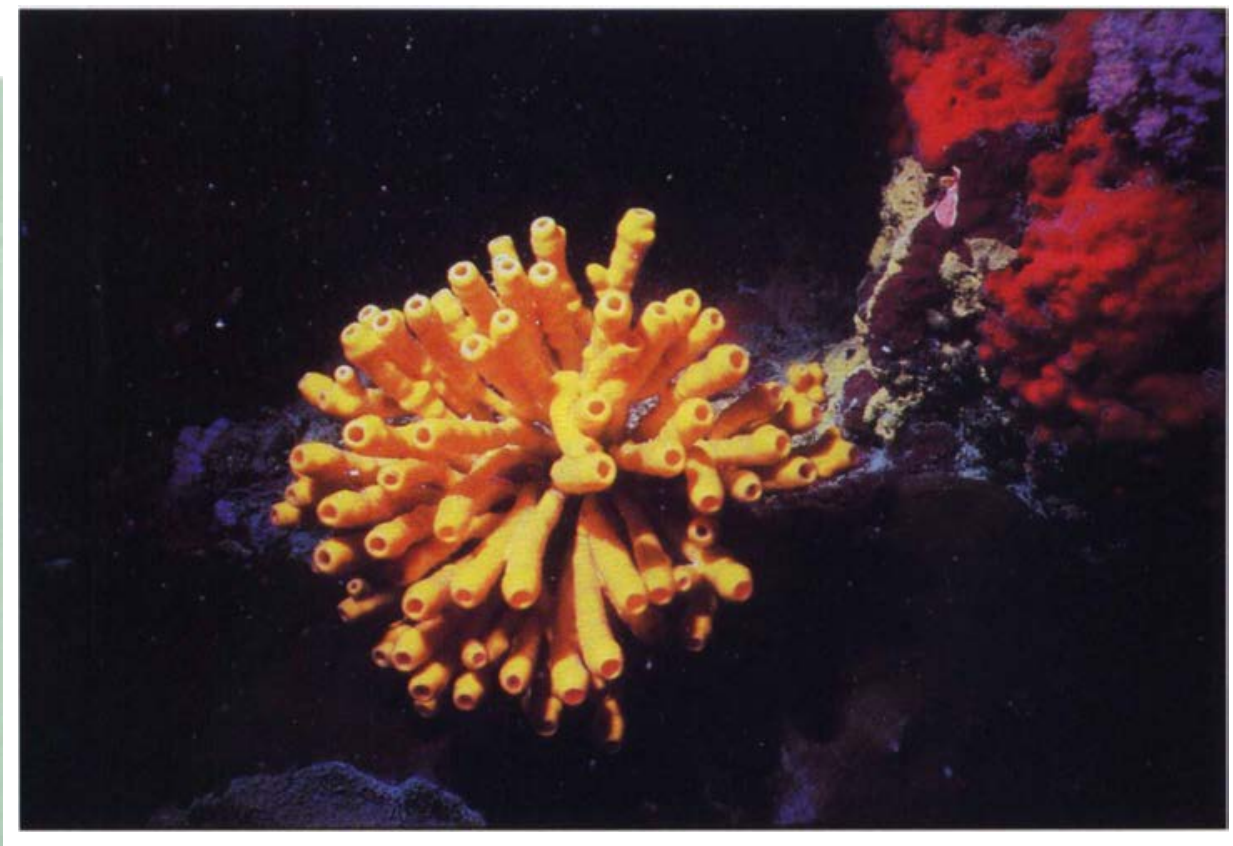

The marine sponge Auletta constricta contains jasplakinolide, a unique molecule currently under study at the National Cancer Institute for the treatment of cancer.

continued from p. 46

responsible for inflammation and pain. Manoalide continues to be widely used throughout the pharmaceutical industry as a molecular probe to provide new insight into the complex processes involved in inflammation. Thus it may well result, through synthetic drug design, in a new class of anti-inflammatory agents.

Perhaps the most important discovery from the Marine Chemistry and Pharmacology Program has been that soft corals contain molecules that are potent inhibitors of inflammation and its associated pain. One important class of compounds, called pseudopterosins, are extracted from the Caribbean soft coral Pseudopterogorgia elisabethae. These compounds were discovered by collaborative chemical and pharmacological studies undertaken by Sea Grant graduate trainees from the Santa Barbara and San Diego campuses. The pseudopterosins have been developed through a licensing agreement with OsteoArthritis Sciences Inc. One new drug, methopterosin (fig. 1), a simple derivative of the natural pseudopterosins, has been developed from this discovery and has been approved by the U.S. Food and Drug Administration for clinical trials.

Methopterosin has a variety of important pharmacological properties that make it suitable for application to a number of conditions, including arthritis, psoriasis and inflammatory bowel disease, among others. Another unique feature of methopterosin is its ability to accelerate wound healing by over $400 \%$, a property of considerable interest in the treatment of burn victims, in postsurgical treatment and in drug therapies for the many disorders involved in the healing process. The combined anti-inflammatory and wound-healing properties of methopterosin assure that this class of marine-derived drugs will be developed for diverse applications.

An unexpected application of the pseudopterosins is as additives in skin care products. International skin care giant Estée Lauder is using "natural extracts" of $P$. elisabethae as additives in a product line called "Resilience." The natural extract produces pronounced reduction of skin inflammation from sunburn or irritation, and it also reduces degeneration of the skin. In the past 2 years, this one application of the pseudopterosins has generated average yearly royalty income of well over $\$ 750,000$ for UC.

Cancer has also been a major focus of Sea Grant research, and there have been significant achievements in this area as well. A unique cyclic compound, jasplakinolide (fig. 1), discovered by both the Santa Cruz and San 